Revista Eletrônica em Gestão, Educação e Tecnologia Ambiental Santa

Maria, v. 20, n. 1, jan.-abr. 2016, p. 105-114

Revista do Centro de Ciências Naturais e Exatas - UFSM

ISSN : 22361170

REGET/UFSM

Revista Eletrônica em Gestão, Educação e Tecnologia Ambiental

\title{
Gerenciamento de Resíduos de Saúde: estudo de caso em estabelecimentos públicos municipais de Pelotas, RS
}

\author{
Health Waste Management: case study in municipal establishments of Pelotas, South Brazil
Simone Colvara Alves ${ }^{1}$, Fernanda Medeiros Gonçalves², Edson Plá Monterosso³ Marcos Vinicius Godecke ${ }^{4}$

\author{
${ }^{1}$ Gestora Ambiental, Universidade Federal de Pelotas (UFPel), Pelotas, RS, Brasil \\ 2Doutora em Produção Animal, Universidade Federal de Pelotas (UFPel), Pelotas, RS, Brasil \\ ${ }^{3}$ Engenheiro Agrônomo, Universidade Federal de Pelotas (UFPel), Pelotas, RS, Brasil \\ ${ }^{4}$ Doutor em Qualidade Ambiental, Universidade Feevale, Novo Hamburgo, RS, Brasil
}

\begin{abstract}
Resumo
Dentre os resíduos de serviços de saúde (RSS), os infectantes preocupam devido ao risco de contaminação ambiental e ocupacional relacionado a falhas de gerenciamento. Sensível à problemática, este trabalho compara situações reais vivenciadas por unidades públicas municipais de saúde no município de Pelotas/RS com o preconizado nas normas e legislações sobre o tema, além de apresentar a unidade de tratamento de RSS do Município, em fase pré-operacional. A metodologia adotada incluiu pesquisa bibliográfica e documental, além de visitas de campo complementadas por entrevistas com servidores municipais envolvidos nesta gestão. Como resultado, na comparação da situação atual com a desejada, foram encontrados problemas que demandam ações corretivas, a exemplo de programas de educação ambiental de atores relacionados a esta gestão. Com relação à unidade de tratamento, a pesquisa mostra os preparativos para a operacionalização de um sistema de autoclave.
\end{abstract}

Palavras-chave: Gestão ambiental governamental. Serviços públicos de saúde. Resíduos de serviços de saúde. Pelotas.

\begin{abstract}
Among the health services waste (RSS), it's possible to attribute some concern in the infective ones since they represent environmental and human contamination risks by inadequate management. With this sensitive aspect, this paper compares real situations experienced by local public health units in the city of Pelotas / RS (South of Brazil) with the recommendations in the Brazilian rules and laws, also showing the pre-operational phase of the treatment unit for this kind of waste. The methodology included bibliographical and documentary research, and field visits complemented by interviews with municipal employees involved in waste management. As a result, when comparing the current situation with the desired, problems that require corrective actions were found, like environmental education programs for stakeholders in relation to this management. Regarding the treatment unit, the study shows some aspects for the operation of an autoclave system.
\end{abstract}

Keywords: governmental environmental management, public health services, health services waste, Pelotas. 


\section{Introdução}

Com a Política Nacional dos Resíduos Sólidos (PNRS), lei federal 12.305/2010, o País passou a contar com um marco regulatório que visa influenciar a rotina de descartes, da dona de casa ao gestor do país, com ações na direção do ainda distante "desenvolvimento sustentável" (BRASIL, 2010).

É notória a reformulação do pensamento da sociedade a partir da ótica ambiental nos dias de hoje, com a população questionando os limites da produção e consumo. As atitudes condizentes com esta realocação de postura vão desde a segregação dos resíduos domiciliares até mesmo a elaboração de planos de gerenciamento de resíduos sólidos (PGRS) pelas pessoas jurídicas (BRASIL, 2010, art. 20). Contudo, a maior parte dos municípios brasileiros ainda destina os resíduos sólidos urbanos de maneira inadequada, encaminhando-os a aterros precários ou lixões (ABRELPE, 2014).

A composição do lixo urbano depende do porte do município, hábitos da população e poder aquisitivo, entre outros fatores, sendo que uma média de publicações brasileiras mostrou em torno de $51,4 \%$ de matéria orgânica, 31,9\% de materiais recicláveis, com o restante $(16,7 \%)$ de outros materiais (BRASIL, 2012). Assim sendo, o primeiro passo para a redução do volume de resíduos lançados diariamente ao meio ambiente seria a segregação das diferentes variedades de resíduos. Tal atitude é essencial quando se trata dos resíduos de serviço de saúde (RSS), visto relacionarem-se diretamente com casos de infecção hospitalar no Brasil (ERDTMANN, 2004).

De acordo com Fadini e Fadini (2001), lixo hospitalar pode ser definido como resíduos que potencialmente podem mocroorganismos ou substâncias nocivas à saúde, produzidos em serviços de saúde, tais como, hospitais, clínicas, laboratórios, farmácias, clínicas veterinárias e postos de saúde.

No Brasil, a expressão "lixo hospitalar", foi substituída por Resíduos de Serviço de Saúde (RSS), conforme as normas da NBR 12.807 e 12.808 (ABNT, 1993b; 1993c). Essa alteração fez-se necessária, pois outras unidades de saúde como laboratórios, clínicas veterinárias, hospitais, postos de saúde, clínicas odontológicas, clínicas médicas, sanatórios e farmácias, também produziam resíduos semelhantes aos gerados no ambiente hospitalar. Desde então, esses resíduos começaram a ter um cuidado especial desde a segregação até a sua destinação final.

A PNRS (BRASIL, 2010, art. 13-g) define resíduos de serviços de saúde como "os gerados nos serviços de saúde, conforme definido em regulamento ou em normas estabelecidas pelos órgãos do SISNAMA e do SNVS", referindo-se ao Sistema Nacional de Meio Ambiente e Sistema Nacional de Vigilância Sanitária, respectivamente. São importantes marcos regulatórios para o gerenciamento dos RSS as normas da RDC 306/2004, da ANVISA e a resolução 358/2005 do CONAMA, que dispõem sobre ações relativas ao manejo, tratamento e disposição final dos RSS (BRASIL, 2004; 2005).

Ainda que a legislação seja clara e específica quanto ao método de descarte, tratamento e destinação final de RSS, muitos municípios brasileiros não possuem um plano de gerenciamento desta classe de resíduos implementado adequadamente, visto que são frequentes notícias veiculadas em meios de comunicação relatando flagrantes de descarte de RSS em lixões a céu aberto. Ainda que um plano municipal de gestão para os RSS represente a base para evitar situações de risco à saúde pública, a imprudência, a falta de conhecimento e a impunidade são os principais motivadores do descarte incorreto (COSTA, 2014).

Para melhor conhecer esta problemática, tendo em vista os riscos relacionados à disposição inadequada dos RSS, este estudo investiga o caso dos serviços de saúde em estabelecimentos públicos municipais de Pelotas, município localizado na região Sul do Rio Grande do Sul, a partir da metodologia apresentada a seguir. 


\section{Metodologia}

O município de Pelotas situa-se a cerca de $250 \mathrm{~km}$ de Porto Alegre, capital do estado, com uma população de aproximadamente 342 mil habitantes (IBGE, 2015).

A coleta de dados envolveu a observação da forma como é realizado o gerenciamento dos RSS em alguns estabelecimentos públicos municipais, comparativamente à orientação preconizada pela legislação vigente e normas ABNT.

A fim de preservar-se a identidade de empresas e locais onde foi realizado o estudo, são chamados de Empresa A, Local B, Local C e Local D. Pelo mesmo motivo foram evitados registros fotográficos de pessoas e da execução da coleta externa.

A Empresa A é a empresa terceirizada contratada para prestar os serviços de coleta de resíduos sólidos em Pelotas, conforme a Lei 12.305/2010. O Local B está sendo preparado para o tratamento local dos RSS, de modo a evitar-se os custos de transporte e destinação final em unidade de tratamento situada na cidade de Sapucaia do Sul, distante cerca de $300 \mathrm{~km}$ de Pelotas. O Local C corresponde a um banco de sangue e o Local $\mathrm{D}$ a um hospital, sendo que ambos atendem pacientes de Pelotas e região. A escolha dos locais C e D baseou-se no fato destes estabelecimentos geram os maiores volumes de RSS, frente às outras instalações de saúde vinculadas ao governo municipal.

As idas aos Locais B, C e D, foram fundamentais para desenvolvimento do estudo, pois possibilitaram a observação in loco as etapas do gerenciamento dos RSS.

Para complemento das informações, foi realizada entrevista não estruturada com técnicos responsáveis pelo gerenciamento dos RSS dos estabelecimentos municipais de Pelotas.

\section{Resultados e Discussões}

Segundo técnicos responsáveis pelo gerenciamento dos RSS, na zona urbana de Pelotas são coletados RSS de 46 estabelecimentos municipais, sendo: 30 unidades básicas de saúde (UBS), 4 estações de tratamento de efluentes (ETE), 3 escolas municipais, 3 centros de assistência psicossociais (CAPS), além do Sindicato Municipal de Pelotas (SIMP), Posto de Atendimento Médico (PAM), Farmácia Municipal, Hemocentro, Pronto Socorro Municipal e Centro de Saúde. Na zona rural são coletados os RSS de 13 postos de saúde. No conjuntos dos estabelecimentos mencionados, a média mensal de coleta situa-se em torno de sete a oito toneladas de RSS.

A visita aos Locais C e D possibilitaram verificar algumas etapas do gerenciamento dos RSS, tais como: manejo, armazenamento e coleta externa, bem como o uso de EPI (equipamento de proteção individual) pelos funcionários responsáveis pelo manejo dos RSS.

Primeiramente foi visitado o Local C, onde a coleta é diária, pois o volume recolhido é em média de dois a três galões de RSS.

O funcionário que faz a coleta é também o motorista do caminhão coletor e na ocasião do acompanhamento vestia calça comprida e camiseta de manga curta com o logotipo da empresa, sapatos fechados e luvas até o punho.

Segundo a NBR 12.809 (ABNT, 1993d) o funcionário, ao entrar no abrigo dos resíduos para fazer a coleta, deve utilizar os seguintes EPIs: gorro, óculos, máscara, uniforme, luvas e botas. A NBR 12.810 (ABNT,1993e) estabelece que o uniforme deverá ser composto por calça comprida e camisa com manga, no mínimo $3 / 4$, de tecido resistente e de cor clara. Já as luvas devem ser de PVC impermeáveis, resistentes e de cor clara.

Comparando essa norma com o que foi observado, verifica-se que os EPIs não estavam em conformidade com a normatização citada. Apesar da resistência em utilizar os EPIs, os mesmos representam uma tecnologia de proteção disponível dentro de uma visão integrada e sistêmica de abordagem dos problemas ocupacionais.

Ao contratar um novo funcionário, é conveniente que a empresa realize curso de capacitação sobre a utilização correta dos EPIs, mostrando a utilidade de cada um dos itens para preservação da saúde 
do trabalhador, expondo os perigos relacionados a não utilização desses acessórios, bem como informar as normas que regulamentam a utilização e as multas aplicáveis.

Em relação aos RSS, os mesmos estavam armazenados dentro de contêineres na cor laranja, sobre o gramado do pátio do estabelecimento, sem cobertura ou proteção lateral, conforme mostra a Figura 1.

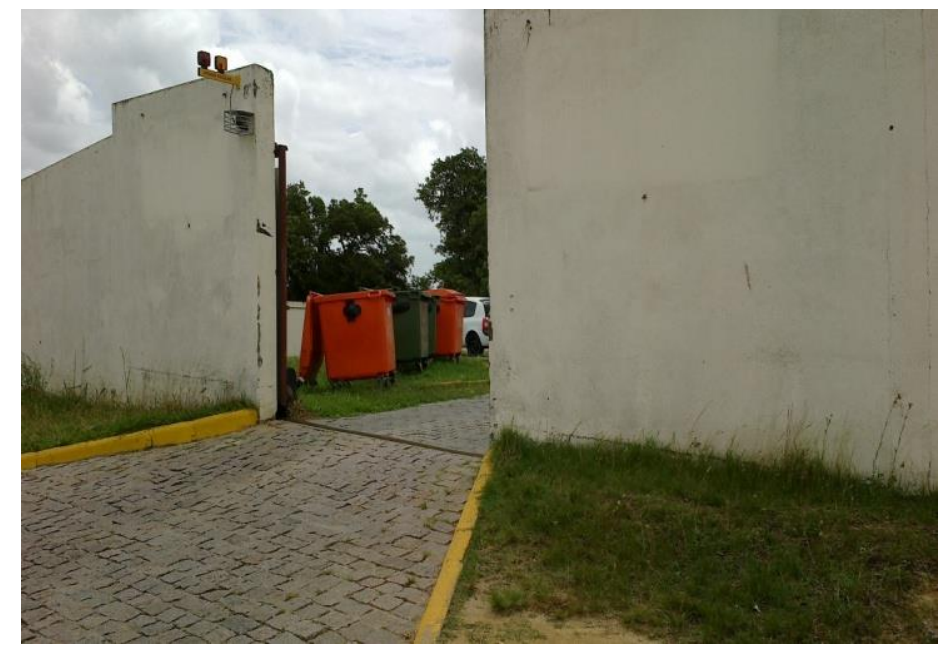

Figura 1 - Contêineres contendo RSS dispostos para coleta externa

Fonte: os autores

O termo biossegurança refere-se a um conjunto de ações destinadas a prevenir, controlar e reduzir ou eliminar riscos inerentes às atividades que possam comprometer a saúde humana, animal e vegetal e ao meio ambiente ou a qualidade dos trabalhos desenvolvidos (BRASIL, 2006). Com vistas à biossegurança, a RDC 50/2002, da ANVISA, estabelece que os RSS devem estar armazenados de forma a garantir a segurança das pessoas, onde o ambiente deve reunir condições físicas estruturais adequadas para impedir a ação do sol, chuva, ventos e demais fatores físicos e químicos e, também o acesso de pessoas não autorizadas ou animais (BRASIL, 2002).

Como os RSS apresentam uma multiplicidade de riscos, de origens e natureza diversas, o local de armazenamento deve conter um espaço para higienização dos carrinhos e contêineres; o ambiente deve contar com boa iluminação e ventilação e ter pisos e paredes revestidos com materiais resistentes aos processos de higienização. Assim, as condições encontradas no Local C não se mostraram aderentes à legislação.

Foi possível observar que os resíduos infectantes foram dispostos em sacos brancos leitosos, obedecendo a NBR 9.190 (ABNT, 1993a), e amarrados na ponta com um nó e com o símbolo de infectante. Todos os resíduos infectantes estavam armazenados dentro contêineres, em conformidade com a NBR 12.809 (ABNT, 1993d).

De acordo com a RDC 306/2004 da ANVISA, os RSS são divididos em cinco grandes grupos (A risco biológico, $\mathrm{B}$ - risco químico, $\mathrm{C}$ - riscos radiativos, $\mathrm{D}$ - não periculosos e $\mathrm{E}$ - perfurocortantes ou escarificantes) onde cada um corresponde a um nível de periculosidade. Os resíduos infectantes são classificados no grupo A e, mesmo em pequena quantidade, devem ser segregados para não comprometer a massa total de resíduos, sendo necessário tratar o todo como resíduo infectante. Neste sentido, a segregação visa atingir metas ambientais e econômicas, minimizando os impactos negativos e diminuindo os custos de tratamento e disposição final. Os sacos brancos, mesmo que estejam dispostos em contêineres, devem estar abrigados em ambientes fechados e isolados de pessoas não autorizadas.

No Local C foi possível observar que os mesmos apresentavam-se dispostos sem proteção superior ou lateral, acessível a animais e a terceiros. Também não havia contenção do chorume produzido por esses resíduos. A disposição dos RSS no Local C mostrou-se de fácil acesso a usuários de drogas, crianças, animais ou transeuntes, resultando em riscos de contágio por agentes patogênicos, além de machucados e cortes, pela presença dos materiais perfurocortantes. 
No manejo com dos sacos plásticos contendo os RSS, observou-se a retirada de dentro dos contêineres "um a um" e disposição em galões azul marinho tampados. Já os objetos perfurocortantes estavam armazenados dentro de caixas Descarpack ${ }^{\circledR}$, ambos com a simbologia de resíduo infectante, conforme a NBR 13.853 (ABNT, 1997).

O Programa de Gerenciamento de Resíduos de Serviços de Saúde (PRGSS), objeto da resolução RDC/ANVISA 306/2004, foi a regulamentação técnica que harmonizou as normas federais no âmbito do Ministério do Meio Ambiente, por meio do Conselho Nacional de Meio Ambiente (CONAMA), e do Ministério da Saúde, através da Agência Nacional de Vigilância Sanitária (ANVISA). Prevê que todos os materiais, limpos ou contaminados por resíduo infectante, deverão ser acondicionados em recipientes com tampa, rígidos e resistentes à punctura, ruptura e vazamento. Em geral, são utilizadas caixas tipo Descartex ${ }^{\circledR}$ ou Descarpack ${ }^{\circledR}$ para o acondicionamento de resíduos do grupo E (perfurocortantes ou escarificantes). A situação encontrada no Local C mostrou-se adequada neste quesito.

Sobre o veículo coletor, foi verificado que as bordas da caçamba apresentavam cantos vivos, com piso de madeira apresentando algumas rachaduras. Ao ser questionado pelas características do veículo coletor, técnico responsável pelo gerenciamento dos RSS comunicou que um caminhão novo foi adquirido pela empresa terceirizada, o qual obedece às especificações da NBR 12.810 (ABNT, 1993e). Dentre outras características, o veículo deve apresentar superfícies internas lisas, de cantos arredondados, de fácil higienização e provido de ventilação adequada.

A segunda visita foi feita no Local D, que atende a população de Pelotas e região.

Em conversa com funcionário foi obtida a informação da coleta de até 15 galões de RSS nos finais de semana e de sete a oito galões durante os dias da semana. A coleta é feita diariamente, conforme a NBR 12.810 (ABNT, 1993e).

Conforme mostra a Figura 2, os resíduos estavam dispostos na rua, sem cobertura e na lateral protegido por grades, armazenados em galões azuis com tampas e com a identificação da empresa coletora e a simbologia de resíduo infectante. Neste dia foram coletados sete galões de RSS.

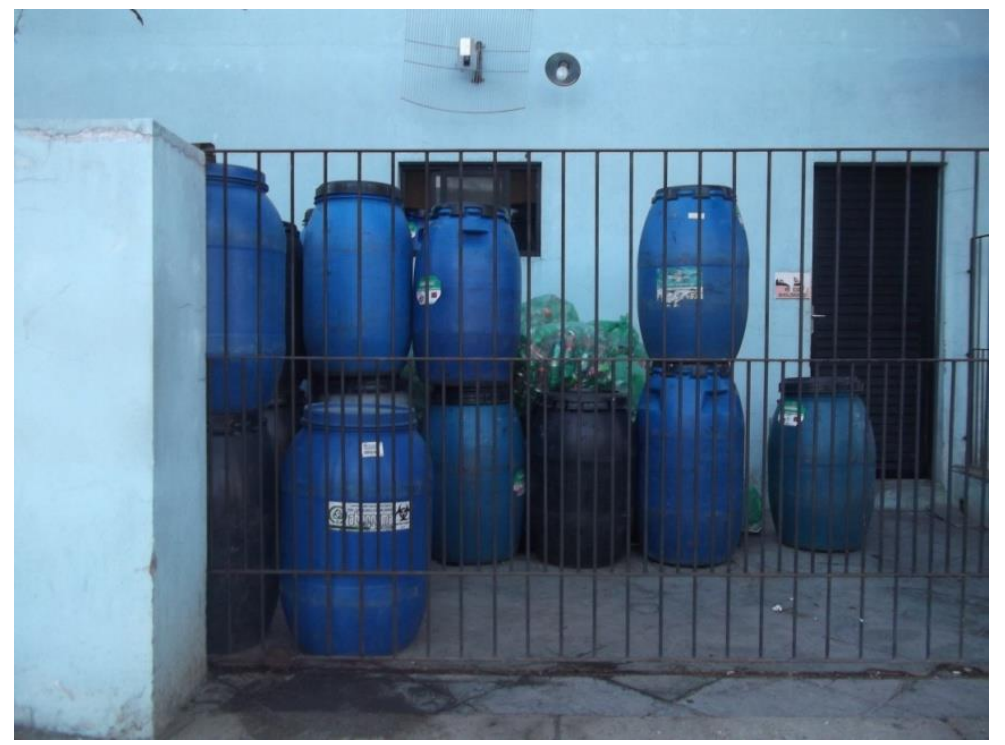

Figura 2 - RSS dispostos para a coleta externa

Fonte: os autores

Na Figura 2 é possível observar que, ao retirar os galões, uma pequena quantidade de líquido ficou exposta no piso. Contudo, imediatamente após a retirada dos resíduos foi feita a limpeza do local, em conformidade com a NBR 12.809 (ABNT, 1993d).

Assim como em C, faz-se necessária a construção de sala de expedição para resíduos temporários no Local D, a fim de proteger os transeuntes e conter o chorume gerado por esses resíduos.

Ao serem retirados os sacos de resíduos dos galões, observou-se que dentro havia, além dos resíduos de saúde, garrafas PET, papéis, sacolas, copos de plástico e demais resíduos comuns. 
De acordo com a resolução CONAMA 5/1993, se a segregação não for feita corretamente, os resíduos comuns (Grupo D), que poderiam ser tratados como resíduos domiciliares, passam a ser considerados como infectantes (Grupo A), necessitando do mesmo tratamento aplicado a estes. Tal resultado implica em perdas econômicas significativas, tendo em vista que o pagamento do serviço ao terceirizado é proporcional às massas e volumes coletados (BRASIL, 1993).

Segundo a NBR 12.809 (ABNT, 1993d), todos os funcionários dos serviços de saúde devem ser capacitados para segregar adequadamente os resíduos e reconhecer o sistema de identificação. Assim, observou-se a necessidade de trabalho de educação ambiental com os atores diretamente envolvidos na segregação dos RSS no Local D.

Devido ao peso dos galões, percebeu-se que o funcionário apresentava dificuldade em colocá-los no caminhão, precisando deitá-los até conseguir colocá-los dentro da caçamba, para então acomodálos na vertical.

Tal situação está em desconformidade com a NBR 12.809 (ABNT, 1993d), a qual estabelece que o transporte dos recipientes deve ser realizado sem esforço excessivo ou risco de acidente para o funcionário. Assim sendo, seria recomendável a atuação de duas pessoas neste procedimento.

O funcionário foi questionado quanto ao fornecimento de equipamentos de proteção individual (EPI) pela empresa, respondendo afirmativamente e mostrando a máscara em local protegido no veículo. Diante desse resultado, o mesmo foi questionado sobre a utilização de tal equipamento durante a coleta. Foi respondido que, como a coleta é feita ao ar livre, não haveria necessidade de utilizá-lo, apenas se fosse feita em ambiente fechado.

Esse procedimento foge ao previsto na NBR 12.809 (ABNT 1993d), a qual estabelece que, para entrar no abrigo de resíduo, o funcionário deve usar os mesmos EPIs utilizados na coleta interna.

A terceira visita técnica foi feita no Local B, mostrado na Figura 3. Trata-se de unidade destinada ao tratamento por autoclave dos RSS oriundos das unidades municipais de saúde de Pelotas. Quando da realização da pesquisa estava pronta para entrar em funcionamento, aguardando apenas o licenciamento operacional.

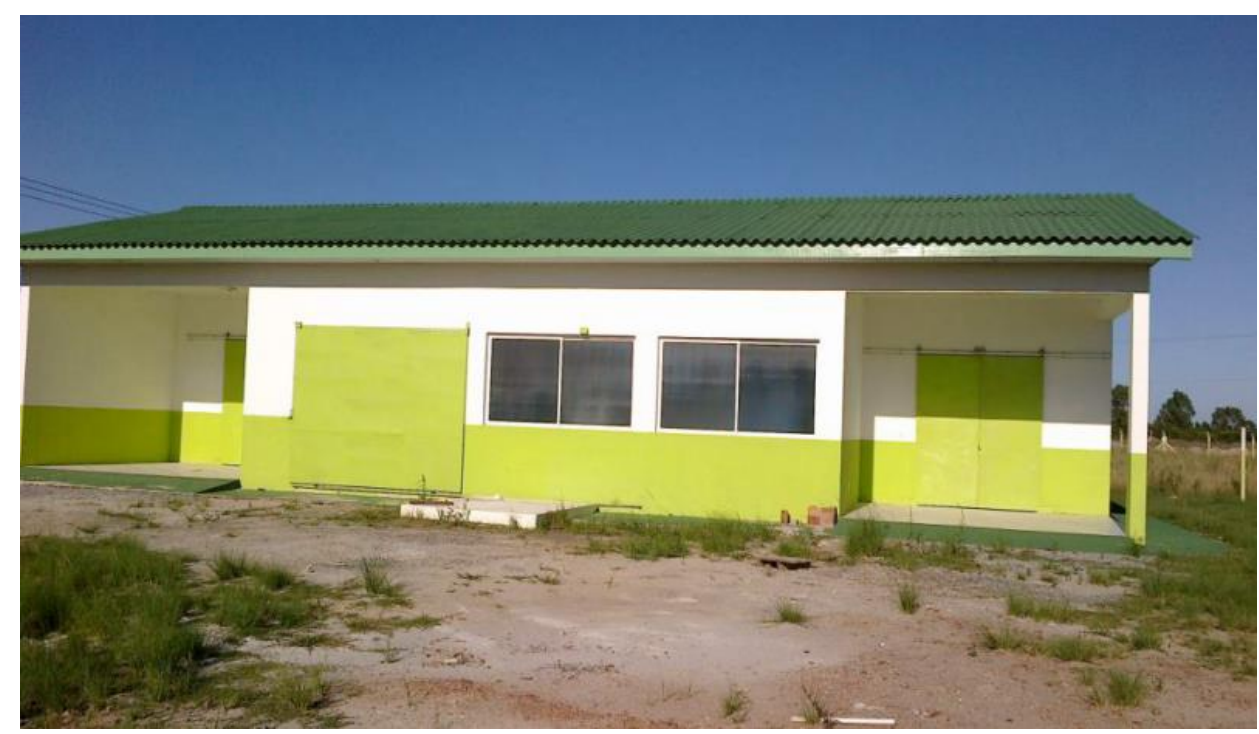

Figura 3 - Futura unidade de tratamento dos RSS municipais de Pelotas Fonte: os autores

Observou-se que o fluxo logístico de B está em conformidade com a RDC ANVISA 306/2004 com relação à infraestrutura física. A resolução estabelece que o trajeto para o traslado dos RSS, desde a geração até o armazenamento externo, deve permitir livre acesso dos recipientes coletores de resíduos, possuir piso com revestimento resistente à abrasão, superfície plana, regular, antiderrapante e rampa, quando necessária, com inclinação de acordo com a RDC ANVISA 50/2002. Também seguiu as orientações da NBR 12.809 (ABNT, 1993d), no sentido do abrigo dos resíduos ter sido construído em 
alvenaria, fechado, com área de ventilação, revestido internamente com material liso, resistente, lavável, impermeável e de cor branca. A Figura 4, extraída do projeto, apresenta o fluxo dos RSS em B.

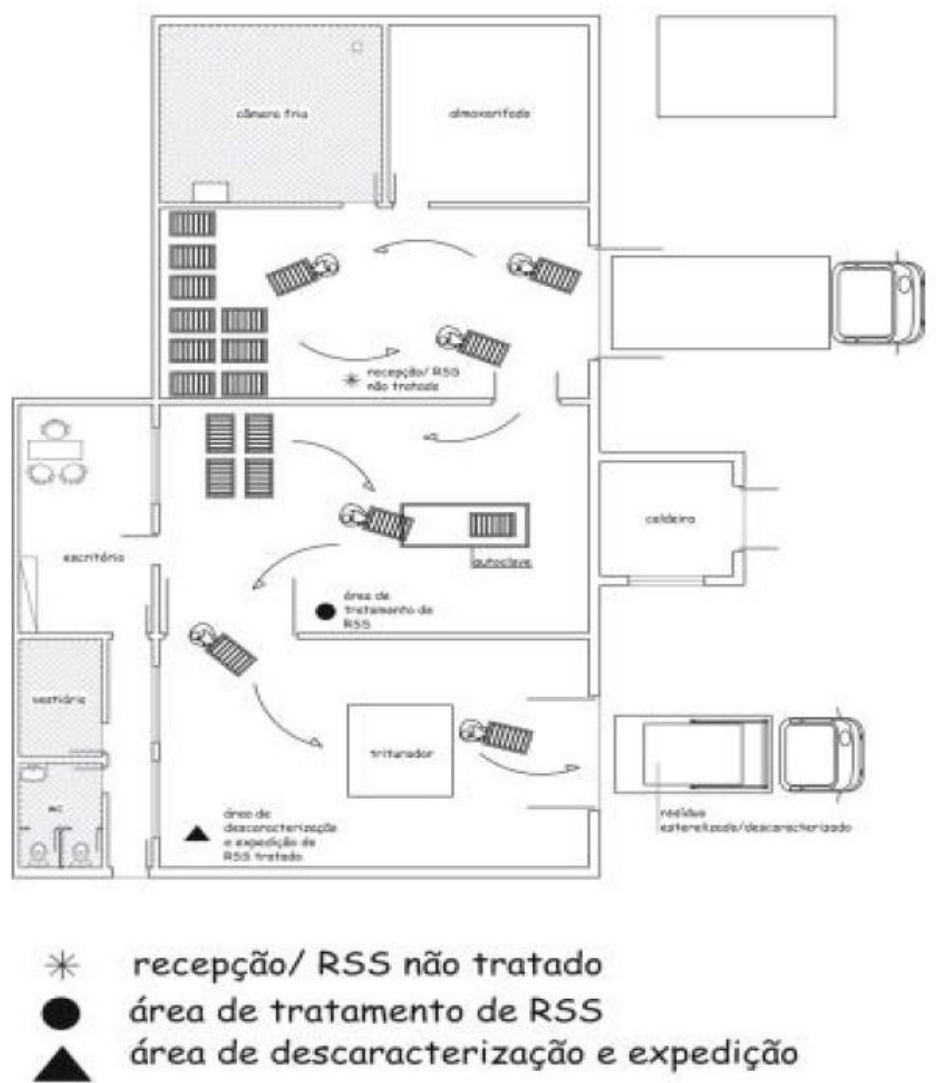

Figura 4 - Fluxo interno dos RSS no Local B Fonte: Monterosso, 2012

Tais precauções são importantes quando considerado o objetivo principal do tratamento dos RSS, da redução ou eliminação dos agentes infecciosos, para que deixem de representar riscos às pessoas e ao meio ambiente a eles expostos (SCHNEIDER, 2004).

O método de esterilização dos RSS previsto para B é por autoclave, normatizado pela NBR 17.6651:2010 (ABNT, 2010). A Figura 5 mostra o autoclave instalado em B.

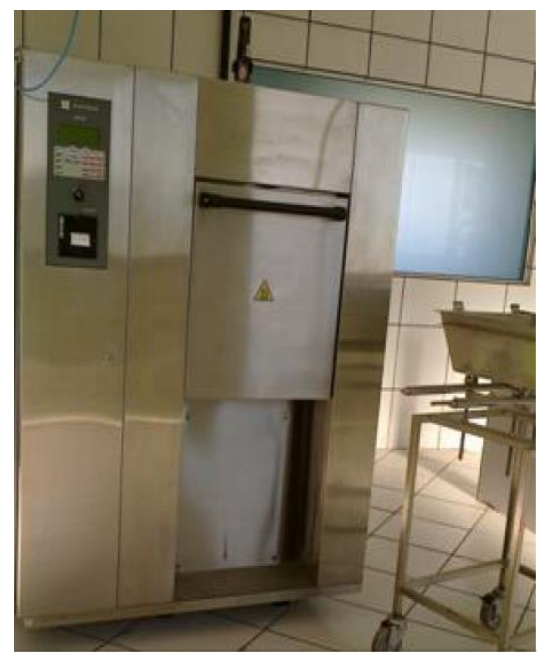

Figura 5 - Autoclave para esterilização de RSS em Pelotas Fonte: os autores 
Após tratados, os resíduos apresentarão forma semelhante aos resíduos sólidos urbanos, conforme mostra a Figura 6A, extraída de Monterosso (2012), porém inertes em termos microbiológicos. Após, os resíduos são levados para o triturador, Figura 6B. Após triturados, os resíduos ficarão descaracterizados e seu volume diminui consideravelmente, conforme mostra a Figura 6C. Por fim, no Local B, serão armazenados na sala de espera, apresentada na Figura 6D, para a expedição como resíduo comum, para disposição em aterro sanitário, visto que não há mais perigo de contaminação biológica.

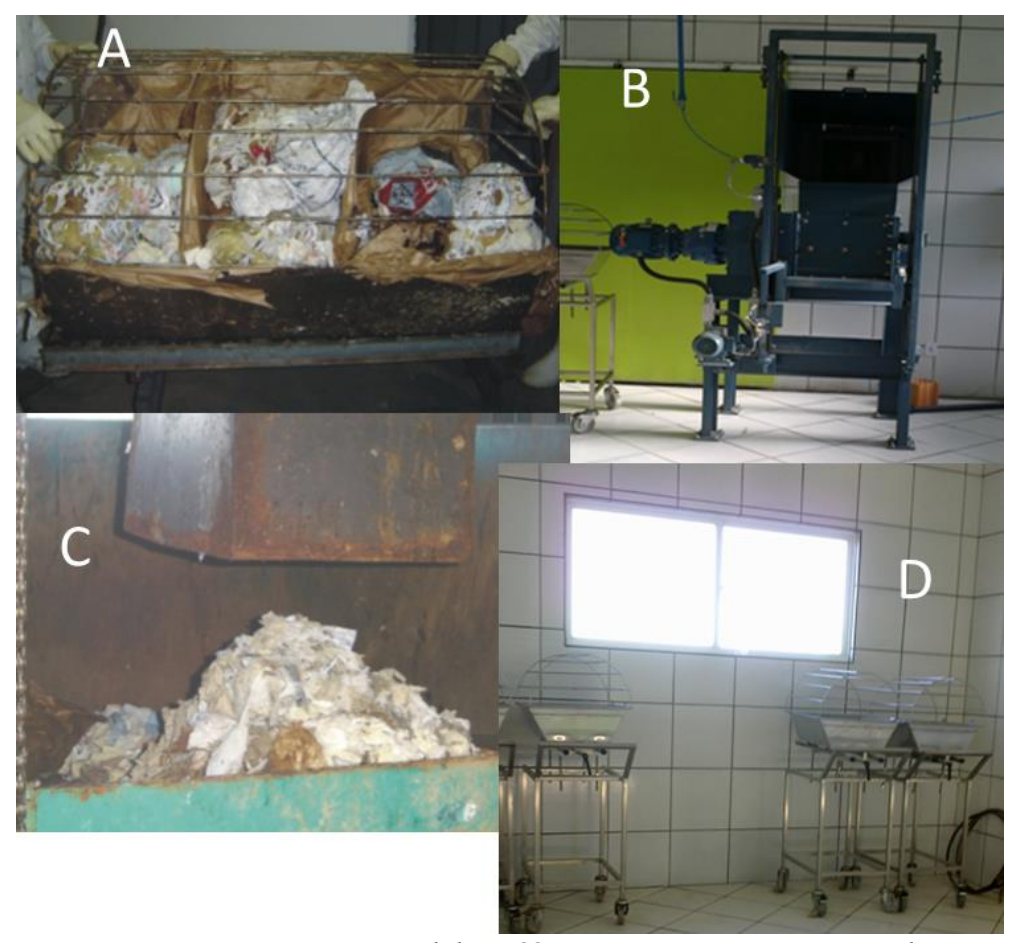

Figura 6 - Processo operacional dos RSS municipais previstos para Pelotas Fontes: A e C Monterosso, 2012; B e D: os autores

A destinação final dos RSS é uma das etapas mais importantes no âmbito socioambiental, pois consiste na disposição definitiva de resíduos no solo ou em locais previamente preparados para recebê-los (BRASIL, 2006).

Os pontos negativos verificados nos locais $C$ e $D$, na comparação da observação de campo com a legislação e normatização vigente, não são crônicos, sendo passíveis de correção quando abordados nos Planos de Gerenciamento de Resíduos Sólidos de Saúde (PGRSS), quando elaborados de acordo com a RDC ANVISA 306/2004, resolução CONAMA 358/2005 e normas do Ministério do Trabalho e Emprego (NR-32), visto que, segundo Schneider et al. (2004), o propósito fundamental de se formular um PGRSS é a redução, tanto quanto possível, dos riscos para saúde da população derivados do manejo de diferentes tipos de resíduos gerados em estabelecimentos de saúde, especialmente aqueles com alto grau de periculosidade.

\section{Considerações Finais}

Conclui-se que há gerenciamento dos resíduos de serviço de saúde (RSS) nos estabelecimentos de competência do governo municipal de Pelotas. Contudo, foi evidenciada a necessidade de melhorias para o pleno atendimento da legislação e normas vigentes, a exemplo do descarte de resíduos comuns, inclusive de materiais recicláveis, misturados aos RSS, resultando em custos desnecessários ao erário público, combinado com um desnecessário aumento dos riscos de contaminação às pessoas, animais e ao meio ambiente.

Assim, faz-se necessário o aprimoramento dos PGRSS de modo a contemplar programas de treinamento destinados aos envolvidos em cada etapa do gerenciamento dos RSS nas diversas 
unidades de saúde do Município, desde a segregação até a destinação final, com intuito de mostrarlhes o correto manejo em cada uma das etapas e sua importância para a redução dos riscos à saúde humana e ambiental. Sugere-se a extensão desta informação aos pacientes e pessoas que estejam de passagem por esses locais, para que façam a sua parte com vistas à racionalização e fluidez do gerenciamento dos RSS.

Destaca-se, ainda, a importância da atuação dos órgãos fiscalizadores deste serviço, tendo em vista a extensão e detalhamento presente na legislação e normatizações da área, bem como os custos envolvidos para a adequada operacionalização, difíceis de serem atendidos por simples altruísmo dos gestores, especialmente de pequenos estabelecimentos de saúde.

\section{Referências}

ASSOCIAÇÃO BRASILEIRA DE EMPRESAS DE LIMPEZA PÚBLICA E RESÍDUOS ESPECIAIS (ABRELPE). Panorama dos Resíduos Sólidos no Brasil 2014. Disponível em: <http://www.abrelpe.org.br/panorama apresentacao.cfm>. Acesso em: 21 set. 2015.

ASSOCIAÇÃO BRASILEIRA DE NORMAS TÉCNICAS (ABNT). NBR 9.190. Sacos plásticos para acondicionamento de lixo: Classificação. Rio de Janeiro : ABNT, 1993.a

NBR 12.807. Resíduos de Serviços de Saúde: Terminologia. Rio de Janeiro : ABNT, 1993.b

NBR 12.808. Resíduos de Serviços de Saúde: Classificação. Rio de Janeiro, ABNT, 1993.c

NBR 12.809. Resíduos de Serviços de Saúde: Manuseio de Resíduos de Serviços da Saúde:

Procedimento. Rio de Janeiro : ABNT, 1993.d

NBR 12.810. Coleta dos Resíduos de Serviços de Saúde: Procedimento. Rio de Janeiro : ABNT, 1993.e

NBR 13.853. Coletores para resíduos de serviços de saúde perfurantes e cortantes: requisitos e métodos de ensaio. Rio de Janeiro : ABNT, 1997.

NBR 17.665-1. Esterilização de produtos para saúde - Vapor. Parte 1: Requisitos para o desenvolvimento, validação e controle de rotina nos processos de esterilização de produtos para saúde. Rio de Janeiro : ABNT, 2010.

BRASIL. Lei 12.305, de 02 de agosto de 2010. Institui a Política Nacional de Resíduos Sólidos. Disponível em: <http://www.planalto.gov.br/ccivil 03/ ato2007-2010/2010/lei/112305.htm>. Acesso em: 21 set. 2015.

Manual de gerenciamento de resíduos de serviços de saúde. Agência Nacional de Vigilância Sanitária (ANVISA). Brasília : Ministério da Saúde, 2006.

Plano Nacional de Resíduos Sólidos. Ministério do Meio Ambiente (MMA). Brasília, agosto de 2012. Disponível em:

$<$ http://www.sinir.gov.br/documents/10180/12308/PNRS_Revisao_Decreto_280812.pdf/e183f0e7-52554544-b9fd-15fc779a3657 >. Acesso em: 11 out. 2015

Resolução RDC 50, de 21 de fevereiro de 2002. Ministério da Saúde. Agência Nacional de Vigilância Sanitária (ANVISA). Disponível em: $<$ http://www.anvisa.gov.br/legis $>$. Acesso em: 7 abr. 2015.

Resolução CONAMA 358, de 29 de abril de 2005. Dispõe sobre o tratamento e a disposição final dos resíduos dos serviços de saúde. Disponível em:

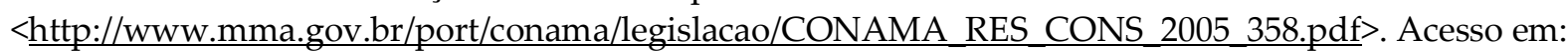
21 set. 2015 
Resolução CONAMA 5, de 5 de agosto de 1993. Dispõe sobre o tratamento e a disposição final dos resíduos dos serviços de saúde. Disponível em:

<http://www.mma.gov.br/port/conama/legiabre.cfm?codlegi=130>. Acesso em: 21 set. 2015

RDC ANVISA 306, de 07 de dezembro de 2004. Dispõe sobre o regulamento técnico para o gerenciamento de resíduos de serviços de saúde. Disponível em: $<$ http://portal.anvisa.gov.br/wps/wcm/connect/10d6dd00474597439fb6df3fbc4c6735/RDC+N\%C2\%BA+ 306,+DE+7+DE+DEZEMBRO+DE+2004.pdf?MOD=AJPERES>. Acesso em: 21 set. 2015

CORRÊEA, L. B.; CORRÊA, E. K. Gestão de resíduos sólidos. Pelotas : Evangraf, 2012.

COSTA, E. Morador denuncia descarte incorreto de lixo hospitalar em Caroebe, RR. G1. Disponível em: <http://g1.globo.com/rr/roraima/noticia/2014/04/morador-denuncia-descarte-incorreto-de-lixohospitalar-em-caroebe-rr.html>. Acesso em: 21 set. 2015.

ERDTMANN, B. K. Gerenciamento dos Resíduos de Serviço de Saúde: Biossegurança e o Controle das Infecções Hospitalares. Texto Contexto Enferm 2004; 13(n.esp):86-93.

FADINI, P. S.; FADINI, A. A. B. Lixo: desafios e compromissos. Cadernos Temáticos de Química Nova na Escola. Edição especial - Maio 2001. Disponível em:

<http://qnesc.sbq.org.br/online/cadernos/01/lixo.pdf>. Acesso em: 21 set. 2015.

INSTITUTO BRASILEIRO DE GEOGRAFIA E ESTATÍSTICA (IBGE). Cidades. Disponível em: <http://www.cidades.ibge.gov.br/xtras/perfil.php?lang=\&codmun=431440>. Acesso em: 21 set. 2015.

MONTEROSSO, E. P. A autoclavagem dentro de uma proposta de gerenciamento de RSS para o Município de Pelotas. Relatório Técnico. Pelotas : Prefeitura de Pelotas, 2012.

SCHNEIDER, V. E. et al. Manual de gerenciamento de resíduos sólidos em serviço de saúde. 2 ed. Caxias do Sul : Educs, 2004. 